\title{
System Thinking to Understand Networked Innovation
}

\author{
Paula Urze ${ }^{1,2}$ and António Abreu ${ }^{3,4}$ \\ ${ }^{1}$ FCT/UNL, Faculdade de Ciências e Tecnologia da Universidade Nova de Lisboa, Portugal \\ ${ }^{2}$ CIUHTC - Centro Interuniversitário de História das Ciências e da Tecnologia \\ ${ }^{3}$ ISEL/IPL - Instituto Politécnico de Lisboa, Portugal \\ ${ }^{4}$ CTS - Uninova - Instituto de Desenvolvimento de Novas Tecnologias \\ pcu@fct.unl.pt, ajfa@dem.isel.ipl.pt
}

\begin{abstract}
Today, knowledge and the capability to create and utilize it are considered to be the main source of a company's sustainable competitive advantage. Within this assumption, the present paper aims at discussing the advantages of applying a system thinking approach in order to deepen the understanding of the factors that leverage or constrain knowledge transfer to support co-innovation, and its impact at a member level, for instance, in terms of the capacity of generating new ideas, processes and products. The paper's empirical section is based on one case study pointed to the largest highway concessionaire in Portugal.
\end{abstract}

Keywords: System Thinking, Innovation, Knowledge Transfer, Collaborative Networks.

\section{Introduction}

Nowadays, globalization has been the main driving force that makes companies run after high levels of performance and competitiveness [1]. According to several authors the business environment has faced dramatic challenges in recent years, where one of the most relevant sources of competitive advantage is innovation capacity [2]. The development of complex products or services requires access to several distinct types of knowledge that companies do not usually hold [3] [4]. As a result, companies can improve their knowledge either from their own assets, making sometimes-high investments, or from the knowledge that may be mobilized through other companies based on a collaborative process [5]. However, recent studies point out that a growing number of innovations introduced in the market come from networks of companies that are created based on core competences of each company. In fact, there is an intuitive assumption that in a turbulent market companies can develop emerging business opportunities and deal with cost/time competitively through an open-innovation environment.

However, it has been difficult to prove its relevance due to the lack of models that support the tools that explain the synergies created in a collaborative environment, which may lead to the reinforcement of innovation flows in a "healthy" collaborative environment [6]. 
The aim of this paper is to present a case study of a Portuguese collaborative network, Brisa co-innovation network, and to discuss the appropriateness of the system thinking approach to understand the dynamics of the processes for innovation in depth.

\section{Knowledge Transfer to Support Co-innovation}

Knowledge has always played an important role in the economy, but only over the last few years has its relative importance been recognized, exactly when its value started growing. Currently, knowledge and the capability to create and utilize it are considered to be the main source of a company's sustainable competitive advantage. to the centrality of knowledge in contemporary society, a shift in our understanding on innovation in business organizations - whether technological, product or strategic innovation, or organizational innovation - is required [7]. Innovation is strongly connected to knowledge: it can be an outcome of novel pieces of knowledge or a novel combination of existing pieces of knowledge; it can also be created during the process of innovation. For example, innovation is a fundamental way of organizational knowledge creation, since it is a process in which the organization creates and defines problems and then actively promotes new knowledge to solve them. As argued by Choo and Bontis [8], a company generates knowledge value from what it knows, through the organizational processes of knowledge creation, knowledge transfer and use of knowledge. Actually, the last decades have shown a generalized concern on the study on how companies create knowledge and how they operate its transfer, in particular.

In knowledge creation, a company generates new knowledge from the conversion and externalization of its tacit, embedded knowledge. The knowledge transfer is shared with a business organization through different functional groups, geographical locations and time periods. Knowledge is transferred between organizations through alliances and networks as well. In terms of knowledge use, the company integrates and coordinates its different types of knowledge in order to produce goods and services. Tacit knowledge plays a crucial role in knowledge creation; codified or explicit knowledge facilitates knowledge transfer; "common knowledge" (common language, shared meanings, overlapping knowledge) or common understanding of the goals and purpose orients knowledge use.

Over time a company incorporates a set of knowledge and skills that is unique to its learning and experience. This stock is the company's intellectual capital, and it includes human, structural and relational capital that exists within its employees, organizational routines, intellectual property and relationships with customers, suppliers, distributors and partners. The stock of intellectual capital is continuously improved through new learning on multiple levels: the individual, the organization and networking organizations of which the company is part.

Moreover, there are contexts where knowledge sharing and transfer constitute a strategic move. Business organizations that belong to highly networked and strongly linked industries, where technologies and markets are still evolving, may strategically share knowledge in order to (1) promote and enable the development of complementary products and services, (2) influence the development of common platforms, dominant designs and de facto or formal standards, and (3) increase a 
critical mass of customers and users. Industries that experience externalities, where the value and the usefulness of a good or service depend on the installed base of connected users, may choose to share knowledge with customers, competitors and collaborators [8]. In addition to network externality effects, companies sharing knowledge may also gain the advantage of increasing benefits by developing a dominant position in an industry or by being an early market leader. The strategic challenge, then, consists on knowing what knowledge to transfer and retain as part of the company's value.

\section{System Thinking Approach to Understand Innovation Dynamics}

The tendency to apply tools where the analysis of reality is mainly based on a linear approach, where the system behavior and its dynamic is explained based on a series of events of one-way relationships, as well as the predisposition to ignore feedbacks and delays might be an obstacle to understand the dynamics of processes for innovation in depth. Furthermore, in a co-innovation context where someone changes a component without considering the interrelationships can cause fixes that backfire, and instead of solving the original constraints, unconsciously increases the barriers to innovation. According to several researches $[9,10]$, the behavior of any system is determined by causal structure rather than specific events. The complexity associated to the behavior of a system usually arises from the interactions (feedback) among the components of the system and not from the complexity of the components themselves. Based on this approach, any system can be described by a set of components that have complex interrelations occurring between them, many of which take the form of feedback loops. It means that a component $A$ may influence a component $B$, which in turn influences component $A$ at a later point. The feedback loops can be positive (or selfreinforcing) or negative (or self-correcting). However, either types of loop can be good or bad, depending on the perspective in which it is analyzed. In order to support the analysis of system behavior, the system thinking approach includes a number of tools that cover several purposes and can be classified in four categories [11], as shown in Figure 1.

\begin{tabular}{|l|l|l|l|}
\hline \multicolumn{1}{|c|}{ Brainstorming tools } & Dynamic thinking tools & Structural thinking tools & Computer-based tools \\
\hline $\begin{array}{l}\text { Double-Q (QQ) } \\
\text { Diagram- similar to }\end{array}$ & $\bullet$ Behavior Over Time & $\bullet$ Graphical Function & $\bullet$ Computer Model \\
Cause and effect & $\bullet$ Causal Loop Diagram (CLD) & $\bullet$ Structure Behavior Pairs & $\bullet$ Management Flight Simulator \\
diagram & $\bullet$ System Archetypes & $\bullet$ Policy Structure Diagram & \\
\hline
\end{tabular}

Fig. 1. System Thinking Tools

\section{System Archetypes}

The system archetypes provide a basic form to describe generic stories and scenarios that can be applied to distinct contexts and environments. Each archetype is built based on a causal loop diagram, and offers a common language to understand the behavior and dynamics of a particular system over time. 
According to some authors [12,13], the most common system archetypes and their storyline are the following:

Success to the Successful - This archetype suggests that the success of a company, project, product, and so forth does not always come from competences but might be due to an initial or starting condition. When two entities compete for a common and limited resource, the entity that initially received the majority of the allocation of resources, fostering in this way its initial success, will receive more resources in the future, increasing its success at the expense of the other. Consequently, the entity that is initially less successful starves for resources and eventually fades out.

Limits to Growth (also known as Limits to Success) - In most real cases, there are commonly some constraints that limit growth, such as resource limits, market saturation, knowledge constraints, and so forth. This archetype suggests that an effort may be initially the cause of the success of an entity. However, the effort reaches a constraint that is inhibiting further growth, slowing down the overall performance over time.

Accidental adversaries - This archetype describes a scenario in which, initially, two entities begin a relationship with the best of intentions, with the purpose of maximizing their respective strengths and minimizing their weaknesses, and based on a "healthy" collaborative environment in order to carry out an objective that cannot be achieved separately. However, the problem arises when one or both parties take action, which in their perspective seems perfectly reasonable, and accidentally undermine their partner's success. The impact of these harmful actions may simply create a sense of frustration and antipathy between the parties, though still partners, or it may get to the point of turning them into hostile adversaries.

Tragedy of the Commons - This archetype describes a scenario where several entities acting in rational self-interest perform activities with the purpose of maximizing their benefits by depleting a common resource. The "tragedy" occurs when the resource capacity is exceeded. The impact of these damages on the Commons may either limit the benefits to the level at which the resource is replenished, or lead to the collapse of the activities performed by all entities in the system.

Growth and Underinvestment - This archetype suggests that when a resource approaches its limit, as market saturation, the life cycle of a product, technology or process is reaching an end. The growth of an entity can only be sustained with investments on more capacity - for an enterprise it means the development of resources, capabilities, competences, and so forth in order to ensure its competitive advantage. However, assuming that the decision not to invest was immediately made and during this period performance degradation occurred; if this pattern is not recognized, the decrease of performance might be used as a justification not to invest in the needed capacity.

Attractiveness Principle - This archetype suggests that, in most real cases, there are multiple restrictions inhibiting the growth or development of some activities, such as in an innovation process, and the solution is to manage the attractiveness of each. Since it is usually impossible to deal with restrictions in the same way and/or all 
cannot be addressed due to limited resources, it is necessary to decide which restrictions should be eliminated first.

Fixes that Fail (also known as Fixes that backfire) - This archetype illustrates a scenario that occurs when a problem symptom exists, and a quick fix is applied with positive results in the short term. However, the solution adopted creates side effects that were not evident at first, worsening the problem in the long term and consequently requiring more fixes.

Escalation - This archetype describes a scenario where the parties believe that just one of them can benefit (win), even in a co-innovation process. In this scenario, there is no absolute goal but instead a relative goal of staying ahead of the other members with the purpose of protecting and/or furthering the company's own best interests. The impact of this harmful behavior may either create a sense of frustration and antipathy between the parties, though still partners, or get to the point of harming their organizations and reducing the value to customers and stakeholders, or even turn them into hostile adversaries.

Shifting the Burden (also known as Addiction) - This archetype illustrates the tension between a solution to solve a problem symptom based on a short-term approach, which solves temporarily the problem (symptomatic solution), and a longterm approach based on a fundamental solution. However, there is frequently a tendency to apply a temporary solution since it is relatively quick and low cost, while a delay is associated to the fundamental solution due to the development of competences, financial limitations, or other constraints. Nonetheless, the implementation of the temporary solution reduces the symptom, which might induce the development of unforeseen side effects, dissipating the need to use the fundamental solution.

Figure 2 illustrates the potential relationships between some "classic" system archetypes discussed above and adapted from [13] for co-innovation.

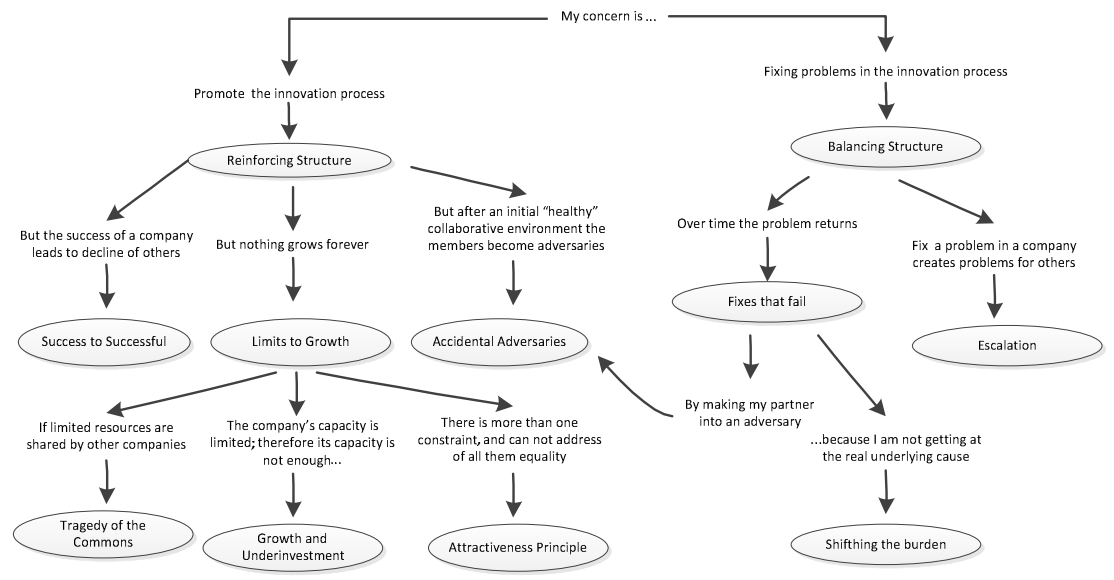

Fig. 2. System Archetype relationships 


\section{$4 \quad$ Innovation Dynamics Analysis Using the System Thinking Approach}

\section{Methodology}

The research has been developed at the largest Portuguese highway ${ }^{1}$, and is based on two main projects developed by Brisa, namely E_TOLL - Electronic Tolling System and ALPR - Advanced License Plat Recognition.

Brisa identified E_TOLL and ALPR as the most relevant projects in terms of innovation. On a first stage, companies and other institutions (technology centers, universities) involved in the projects were contacted and invited to cooperate with our research. Empirical data stems from two main sources: in-depth interviews conducted with key participants belonging to the network, and a brief survey. The involvement of various partners in the network is critical in order to foster a spirit of openness and cooperation in this fundamental process.

Brisa Case Study. The Brisa company currently operates a network of eleven highways on a concession basis, with a total length of around $1096 \mathrm{~km}$, constituting the main Portuguese road links. Given its importance and dimension, Brisa owns several companies specialized in motoring services and aimed at improving the quality of the service provided to customers and increasing its own operating efficiency. The Brisa co-innovation network is a long-term collaborative network.

In order to analyze the sustainability of Brisa co-innovation network, as first approach, an effort to find some similarity to the most common aforementioned system archetypes was made. Taking into account the data collected and the archetypes' causal loop diagram, the choice fell on Shifting the Burden archetype, whose causal loop diagram is illustrated in Figure 3a, and on an adjustment of the Tragedy of Commons, whose causal loop diagram is illustrated in Figure $3 b$.

The application of Shifting the Burden archetype to Brisa supports the proposition that in order to respond to market demands (problem symptom) Brisa had to make a choice between a symptomatic solution that was based on product and service purchase, or develop competences to support innovation (fundamental solution).

However, the development of competences requires access to several distinct types of knowledge that Brisa needed to develop, and this process has a significant time delay before it has an effect on the original problem symptom (respond quickly to market needs). This disadvantage led Brisa to choose the acquisition of products and services (symptomatic solution). Over a long period of time, Brisa's managers believed that the problem symptom was supposedly solved by applying the symptomatic solution as the acquisition of products and services caused a decrease in the original problem symptom, keeping it in balance. Additionally, the recurrent use of the symptomatic solution induces the development of unforeseen side effects, which reinforce the justification not to invest in the fundamental solution. However, in order to increase its competitiveness, Brisa's managers decided to invest in the

\footnotetext{
${ }^{1}$ The present results are based on research work developed under the project - DIINOV DINÂMICAS DE TRANSFERÊNCIA DE CONHECIMENTO EM REDE DE INOVAÇÃO, FCT/UNL, BRISA, ISEL/IPL, 2014.
} 
fundamental solution, promoting new knowledge from their own assets as well as from knowledge mobilized through other companies and organizations, such as universities and government institutes based on an open-innovation environment. Nowadays, Brisa co-innovation network is a long-term collaborative network that has more than 30 members from several domains and business activities (e.g., research institutions, universities, associations, governmental entities, start-ups, business angels, and suppliers), and its sustainability can be explained based on an adjustment of the Tragedy of the Commons.

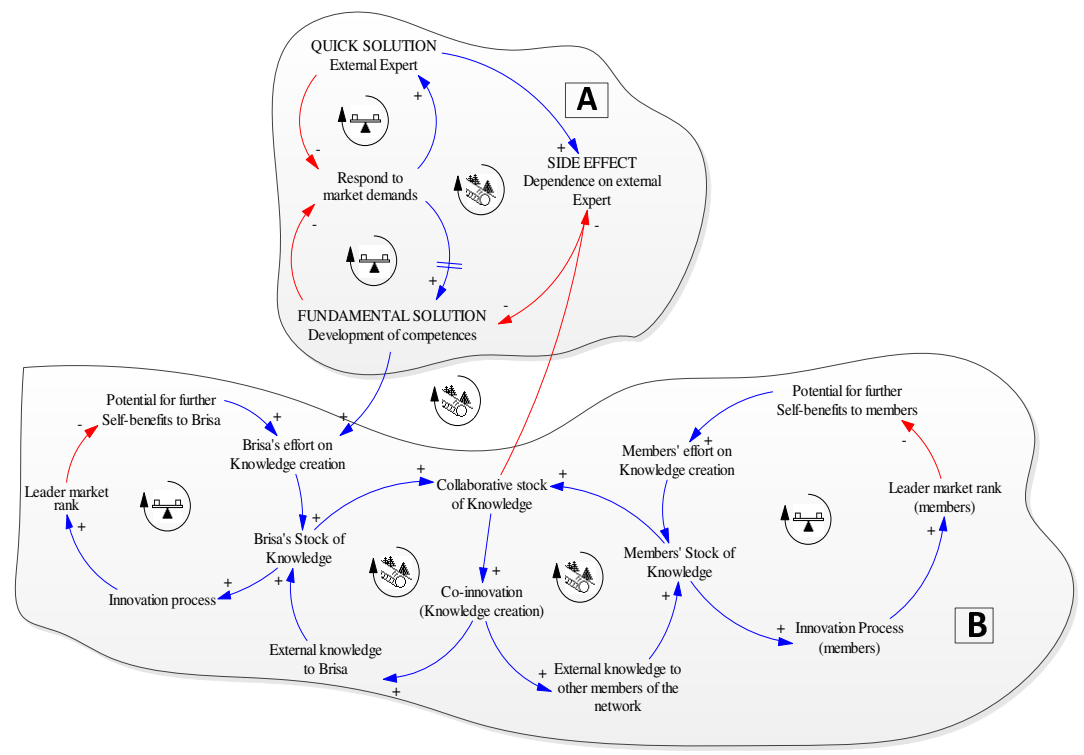

Fig. 3. (a, b) - Causal Loop Diagram

The original causal loop diagram that explains the pattern of this archetype, previously described, includes two reinforcing loops on the outside that represent individual efforts and benefits, and two balancing loops on the inside that represent collective efforts and benefits. However, an adaptation of this archetype can illustrate another useful scenario where the synergies created in a collaborative environment lead to the reinforcement of innovation flows, and the co-innovation benefits (knowledge creation) are greater than the sum of individual knowledge creation due to the establishment of a concerted effort. In this adapted archetype the reinforcing loops are on the inside and represent collective efforts and benefits, and the balancing loops are on the outside and represent individual efforts and benefits.

Furthermore, from the aggregation of the two archetypes a reinforcing loop arises (side effect, fundamental solution, Brisa's effort on knowledge creation, Brisa's stock of knowledge, and collaborative stock of knowledge), which reinforces the justification to invest in the fundamental solution. 


\section{Conclusion}

This work discussed the system thinking approach and the general system archetypes applied to co-innovation in a collaborative context.

The development of models to understand the dynamics of co-innovation processes in depth in collaborative environments will not only help to better understand this area, but also contribute to a wider adoption of the collaborative network paradigm as a way to develop capabilities that will enable companies to respond quickly to market needs.

Some preliminary steps in this direction, inspired in system thinking concepts, were presented. Initial results illustrate the applicability of the suggested approach. The application of archetypes to Brisa network reinforces the choices made by the company. The results seem to bring benefits in terms of developed synergies in a collaborative environment, which promotes innovation flows.

Further steps are necessary toward the elaboration of a robust tool as well as to its validation.

Acknowledgments. This work was partially supported by BRISA Innovation and Technology (BIT) through a research and development project.

\section{References}

1. Tidd, J., J. Bessant, and K. Pavitt (2005). Managing Innovation: Integrating Technological, Market and Organizational Change Hong Kong: John Wiley \& Sons, Ltd.

2. Argote, L., et al. (2000). Knowledge Transfer in Organizations: Learning from the Experience of Others. Organizational Behavior and Human Decision Processes, 82(1).

3. Urze, P., Abreu A. (2012) Knowledge transfer assessment in a co-innovation network, Collaborative Networks in the Internet of Services, in Camarinha-Matos, Luis M.; Afsarmanesh, Hamideh (Eds.) IFIP, Springer.

4. Urze. P; Abreu A. (2013) Circulation of Knowledge in a co-innovation network: An assessment approach, Collaborative Systems for Reindustrialization in Camarinha-Matos, Luis $M$ and Sherer, Raimer J. IFIP Springer.

5. Abreu, A. and L.M. Camarinha-Matos (2010). Understanding Social Capital in Collaborative Networks, in Balanced Automation Systems for Future Manufacturing Networks - IFIP AICT 322, Springer. p. 109 - 118.

6. Abreu, A., P. Macedo, and L.M. Camarinha-Matos (2008) Towards a methodology to measure the alignment of value systems in collaborative networks, in Innovation in Manufacturing Network, A. Azevedo, Editor, Springer: p. 37- 46.

7. Nonaka, I. (1994) A Dynamic Theory of Organsational Knowledge Creation, Organisational Science 5 (1): 14-37.

8. Choo, C. W. and Bontis, N. (2002) Knownledge Intellectual Capital, and Strategy, The Strategic Management of Intellectual Capital and Organisational Knowledge, Oxford University Pressp 3-19. 
9. Ford, David N. and Taylor, Tim. (2005). "Why Good Projects Go Bad: Managing Development Projects Near Tipping Points." Proceedings of the 23rd International Conference of the System Dynamics Society.

10. Sterman, J.D. (2000). Business Dynamics - Systems Thinking and Modeling for Complex World. 2000: McGraw-Hill.

11. Daniel H. Kim (2000). Systems Thinking Tools, A Users Reference Guide, Pegasus Communications.

12. Rahn, Joel, R. (2005). "Fear and Greed: A Political Archetype." Proceedings of the 23rd International Conference of the System Dynamics Society. Boston, MA.

13. Senge, Peter (1994). The Fifth Discipline Fieldbook: Strategies and Tools for Building a Learning Organization. Doubleday. 